\title{
Analyzing the Climate Change Impact and Farmer's Adaptability Strategies in Khyber Pakhtunkhwa, Pakistan ${ }^{\dagger}$
}

\author{
Khuram Nawaz Sadozai 1,*, Munawar Raza Kazmi ${ }^{2}$, Muhammad Israr Khan ${ }^{3}$ and \\ Sonia Sonia ${ }^{4}$ \\ 1 Department of Agricultural \& Applied Economics, Faculty of Rural Social Sciences, The University of \\ Agriculture Peshawar, Peshawar 25000, Pakistan \\ 2 Australian Centre for International Agricultural Research, Islamabad 44000, Pakistan; \\ munawar.kazmi@aciar.gov.au \\ 3 The Government of Khyber Pakhtunkwa, Peshawar 25000, Pakistan; misrar04@gmail.com \\ 4 Department of Economics, University of Reading, Reading RG6, UK; sonia2@pgr.reading.ac.uk \\ * Correspondence: ksaddozai@aup.edu.pk; Tel.: +92-300-5926494 \\ † Presented at the third International Tropical Agriculture Conference (TROPAG 2019), \\ Brisbane, Australia, 11-13 November 2019.
}

Published: 10 April 2020

\begin{abstract}
The agriculture sector is deemed as more vulnerable to climate change as its variation can directly affect the crop's productivity. However, climate change impact and farmers adaptation strategies were not figured out in Khyber Pakhtunkhwa Province, Pakistan by previous researchers and formed the rationale for this research endeavor. This research has assessed the Climate Change impact on wheat productivity and farmers adaptability strategies. The non-climatic variables (wheat yield and area under wheat cultivation) and climatic variables (temperature, precipitation and humidity) were taken into consideration. The Panel Data of thirty years (1985-2015) about non climatic and climatic variables was obtained from different secondary sources; however, primary data was collected from sampled farmers. The econometric diagnostic tests were encompassed to confirm the validity of the data. Chow test was used to underscore the structural breaks. Fixed Effect Model was adopted as suggested by Hausman Test. The salient findings express that temperature has inverse relationship with wheat productivity. This implies that by soaring one Celsius degree Centigrade $\left({ }^{\circ} \mathrm{C}\right)$ temperature can plunge down the wheat productivity by 0.074 percent. Similarly, the association of precipitation was also observed negative with wheat. Contrary to this, humidity is observed as positively associated with wheat. The study concludes the substantial association of climate change with wheat crop, whereas, farmers had less awareness about the adoptability strategies. It is recommended that high temperature resistant wheat varieties may be provided to farmers and disseminates the exalted adaptation strategies with respect to climate change to overhaul their existing crop management practices.
\end{abstract}


Keywords: climate change; wheat; fixed effect model \& farmer's adaptability strategies

(c)
(C) 2020 by the authors. Licensee MDPI, Basel, Switzerland. This article is an open access article distributed under the terms and conditions of the Creative Commons Attribution (CC BY) license (http://creativecommons.org/licenses/by/4.0/). 